University of Wollongong

Research Online

Faculty of Engineering and Information

Faculty of Engineering and Information

Sciences - Papers: Part A

Sciences

$1-1-2011$

\title{
An adaptive design approach for geothermal plant with changing resource characteristics
}

M Imroz Sohel

Scion, msohel@uow.edu.au

Mathieu Sellier

University of Canterbury

Susan Krumdieck

University of Canterbury

Follow this and additional works at: https://ro.uow.edu.au/eispapers

Part of the Engineering Commons, and the Science and Technology Studies Commons

Research Online is the open access institutional repository for the University of Wollongong. For further information contact the UOW Library: research-pubs@uow.edu.au 


\title{
An adaptive design approach for geothermal plant with changing resource characteristics
}

\begin{abstract}
Geothermal power plants are designed for optimal utilization of geothermal resource. However, geothermal fields typically undergo significant changes in resource characteristics such as pressure, temperature and steam quality over their life span. With appropriate reservoir modelling it is possible to predict the future resource characteristics of a geothermal field to a reasonable degree of accuracy. We propose a new adaptive design approach that would allow geothermal power plants to take into account the change of resource characteristics that occur over a 30-40 years time horizon based on the results of reservoir modelling. Currently, it is difficult and expensive to modify or renovate an existing plant due to space constraints, piping arrangements, transportation of machinery etc. The adaptive design approach would allow cost effective modifications in operation and equipment to adjust to changes in resource characteristics in the future. A simple model for a typical combined cycle geothermal power plant is considered as a test case for the adaptive design approach. Simulation is carried out using changes in both wellhead specific enthalpy and mass flow rate. There are four case studies presented in this paper that analysed various possible options of the hypothetical power plant depending on the changes in resource characteristics. Taking into account the results of the simulation, alternative plant designs are presented and improvements in performance are discussed. Although, the initial investment cost might go up as a consequence of adaptive design, over the life span of the plant the total benefit may be greater.
\end{abstract}

\section{Keywords}

approach, geothermal, plant, changing, resource, adaptive, characteristics, design

\author{
Disciplines \\ Engineering | Science and Technology Studies
}

\section{Publication Details}

Sohel, M. Imroz., Sellier, M. \& Krumdieck, S. (2011). Adaptive design approach for geothermal plant with changing resource characteristics. World Renewable Energy Congress (pp. 1-8). 


\title{
An adaptive design approach for a geothermal plant with changing resource characteristics
}

\author{
M. Imroz Sohel ${ }^{1,{ }^{*}}$, Mathieu Sellier ${ }^{2}$, Susan Krumdieck $^{2}$ \\ ${ }^{I}$ Scion, Te Papa Tipu Innovation Park, 49 Sala Street, \\ Rotorua, New Zealand \\ ${ }^{2}$ Department of Mechanical Engineering, University of Canterbury, Private bag 4800, \\ Christchurch, New Zealand \\ * Corresponding author. Tel: +64 7 3435730; fax: +64 7 3435375; E-mail address: \\ mohammed.sohel@scionresearch.com
}

\begin{abstract}
Geothermal power plants are designed for optimal utilization of geothermal resource. However, geothermal fields typically undergo significant changes in resource characteristics such as pressure, temperature and steam quality over their life span. With appropriate reservoir modelling it is possible to predict the future resource characteristics of a geothermal field to a reasonable degree of accuracy. We propose a new adaptive design approach that would allow geothermal power plants to take into account the change of resource characteristics that occur over a 30-40 years time horizon based on the results of reservoir modelling. Currently, it is difficult and expensive to modify or renovate an existing plant due to space constraints, piping arrangements, transportation of machinery etc. The adaptive design approach would allow cost effective modifications in operation and equipment to adjust to changes in resource characteristics in the future. A simple model for a typical combined cycle geothermal power plant is considered as a test case for the adaptive design approach. Simulation is carried out using changes in both wellhead specific enthalpy and mass flow rate. There are four case studies presented in this paper that analysed various possible options of the hypothetical power plant depending on the changes in resource characteristics. Taking into account the results of the simulation, alternative plant designs are presented and improvements in performance are discussed. Although, the initial investment cost might go up as a consequence of adaptive design, over the life span of the plant the total benefit may be greater.
\end{abstract}

Keywords: Geothermal power, resource characteristics change, adaptive design, low temperature power source.

\section{Introduction}

We are at a point of time when on one hand, the negative effects of anthropogenic atmospheric alteration are more evident than ever, and on the other, the demand for energy is ever increasing. Although it claimed that there exists a vast reserve of fossil fuel, field by field petroleum production is decreasing [1]. The huge challenge of emission reduction, growing energy demand and peak oil can be approached in two ways. Firstly, by improving energy conversion efficiency of traditional energy sources and secondly, switching to more and more renewable energy sources. Unfortunately, most renewable energy sources are dependent on climatic variation and are not suitable for base load operations. Geothermal energy, on the contrary, provides a clean, reliable source of renewable energy. Energy concentration in geothermal sources is much higher than in many other renewable sources. Moreover, geothermal power plants are considered to have significant lower $\mathrm{CO}_{2}$ emissions than a standard combined cycle power plant or a pulverized coal fired power plant [2].

Current research and development trends towards geothermal power generation, specifically, low temperature power cycles are noticeable [3-12]. Geothermal power plants are generally designed based on constant resource characteristics. However, it has been observed in many plants that the resource characteristics change significantly throughout the lifetime of the plant [13]. Consequently, deterioration of plant performance and unplanned design changes occur. However, geothermal power plants are very capital intensive and it is not very easy to change a plant to adapt to resource characteristics different from the original design. 
By appropriate reservoir modelling, it is possible to predict future resource characteristics depending on various parameters including the rate of resource utilization, the percentage of brine reinjection etc [14]. In this paper we propose an adaptive design approach where provisions are kept for a plant to adapt to resource characteristics changes at the time of building which may save a great deal of effort and money in the long run. We have presented several case studies to demonstrate the benefit of the adaptive design approach.

\section{Methodology}

We have taken a hypothetical combined cycle geothermal power plant for our study. The geothermal fluid is a mixture of steam and brine. Steam is separated from the brine in a suitable separator then used to power a steam turbine. The exhaust steam from the steam turbine is used to power bottoming organic Rankine cycle units (BOT-ORC). The separated brine is also used in other organic Rankine cycle units (BRN-ORC). After the heat recovery, both condensed steam and geothermal brine are mixed together and reinjected to the reservoir. Pentane is used as the working fluid in the binary cycles. Fig. 1 shows a schematic of the hypothetical power plant. The base case considered here has four BOT-ORCs and two BRNORCs as presented in Fig. 1.

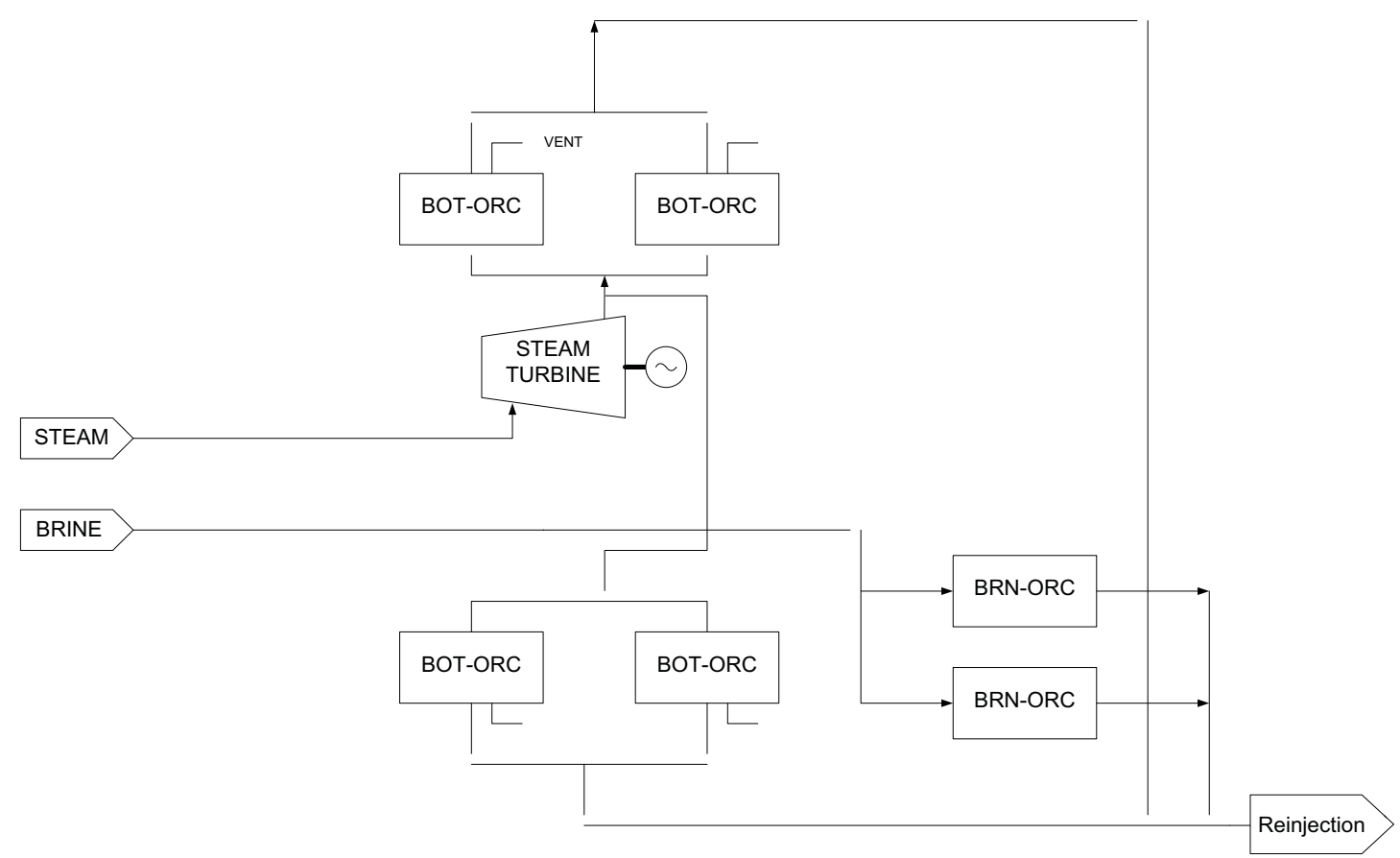

Fig. 1. Schematic diagram of the combined cycle geothermal power plant.

\subsection{The component model}

Simple models have been used for the analysis presented here. Independent component modules are developed in Matlab/Simulink [15] which can be connected later to develop a system model. The thermo-physical properties are calculated using the REFPROP [16] database. The working fluid flow round the cycle and each process may be analysed using the energy conservation, mass conservation and entropy generation applied to a system boundary around each system component. Changes in kinetic energy and potential energy may be neglected and equilibrium conditions can be assumed at the cross-sections of both inlet and outlet. Detailed discussion on the modelling of these ORCs is available in our previous work [9]. 


\subsection{The Resource Affected Performance Model}

A geothermal field passes through four different phases or periods [13]: (1) development, (2) sustainment, (3) decline and (4) renewable. During the last phase, a geothermal resource approaches the ideal of a sustainable and renewable resource. To attain this pahse requires prudent management of the resource. In a Resource Affected Performance Model (RAPM) we change the geothermal resource characteristics and observe the effect on plant performance. We assume that the reservoir modelling predicts that the geothermal resource enthalpy will increase from about $1400 \mathrm{~kJ} / \mathrm{kg}$ to $2000 \mathrm{~kJ} / \mathrm{kg}$ over the life time of the power plant. An adaptive design approach is discussed here which keeps provision for this change in resource characteristics.

Applying conservation of mass at the well head

$$
\dot{m}_{T}=\dot{m}_{b}+\dot{m}_{s}
$$

where, $\dot{m}_{T}$ is the total mass flow rate at the well head, $\dot{m}_{b}$ is the brine mass flow rate and $\dot{m}_{s}$ is the steam mass flow rate. Dividing Eq. (1) with $\dot{m}_{T}$ yields

$1=C_{b}+C_{s}$

where, $C_{b}$ is defined as brine content and $C_{s}$ is defined as steam content. It is advantageous to express resource characteristics as steam content $\left(C_{s}\right)$. Applying energy balance at the well head

$\dot{m}_{T} h_{R}=\dot{m} h_{b}+\dot{m} h_{s}$

where, $h_{R}$ is the resource enthalpy, $h_{b}$ is the enthalpy of the brine (saturated liquid) and $h_{s}$ is the enthalpy of the steam (saturated vapour). The reinjection temperature is calculated from the energy balance of mixing of brine and condensate before reinjecting to the geothermal field.

$$
\dot{m}_{T} h_{R N G}=\dot{m}_{b} h_{b}+\dot{m}_{c} h_{c}
$$

where $R N G$ stands for reinjection, $b$ stands for brine and $c$ stands for condensate.

From Eq. (2), if the steam content of a geothermal field $\left(C_{s}\right)$ increases, the brine content $\left(C_{b}\right)$ must be reduced and vice versa. If we want to keep $\dot{m}_{b}$ and $h_{b}$ unchanged as $C_{s}$ increases or decreases, we must manipulate parameters of the left hand side of Eq. (3). Since, $h_{R}$ is the parameter characterised by geothermal resource, we may not want to manipulate it. The only suitable solution would be to control the geothermal fluid flow rate $\left(\dot{m}_{T}\right)$. When $C_{s}$ increases, we can keep $\dot{m}_{b}$ constant by using condensate recirculation and increased geothermal fluid flow rate $\left(\dot{m}_{T}\right)$. If we are interested only on the constant heat transfer in the vaporizer, the reinjection temperature (i.e. brine outlet temperature) can be lowered. The following assumptions are made for the RAPM. 
1. Operating state points of the geothermal power plant remain unchanged i.e., the change in mass flow rate in steam and brine are only responsible for the change in overall heat transfer coefficient.

2. To control the vaporizer steam outlet condition, excess steam is vented to the atmosphere.

3. The off-design well-head condition is always within the wet-steam zone i.e., there is no change in temperature at the well head and the geothermal fluid is a mixture of steam and brine.

\section{Results}

There are four case studies presented which analyze adaptive design approach to address the change in geothermal resource characteristics. These case studies present four possible solutions for the assumed future resource characteristics.

\subsection{The base case}

Normally, each turbine has an operating limit and for the steam turbine it has been fixed to 37 MW. For the pentane turbine the maximum power is fixed at 7 MW. Fig. 2 shows the plant output in the base case as the resource enthalpy increases. With increasing steam content from about $25 \%(1400 \mathrm{~kJ} / \mathrm{kg})$ to about $35 \%$, the steam turbine reaches its maximum and produces the same power thereafter. Since the steam turbine is unable to utilize the excess steam, the bottoming cycle is receiving condensate at an elevated mass flow rate. Therefore, the power output of the BOT-ORC increases and owing to a lack of brine, the BRN-ORCs are producing much less than their capacity.

\subsection{Case study 1: increased geothermal fluid flow rate}

The reduced brine flow problem can be tackled in many ways. If one uses excess geothermal brine to reheat the condensate collected from the BOT-ORC, an increased mass flow of brine can be ensured for the BRN-ORC. Fig. 3 presents a schematic diagram of such a design. Here, more power is being produced at the expense of more geothermal fluid, which means the resource is being utilized at a higher rate; not necessarily ensuring optimum utilization. Fig. 4 shows a corresponding improvement in plant performance by adopting this approach. It is noticeable from Fig. 4 that the BRN-ORC produces gradually less power from $25 \%$ steam content to $35 \%$ then its power production is independent of steam content. Since, it is more efficient to directly expand steam in a turbine to produce power than in bottoming cycle, one should utilize as much steam as possible in the steam turbine within its manufacturing limit. By increasing the geothermal fluid flow rate, the brine reinjection temperature does not change much.

\subsection{Case study 2: upgrading the steam turbine}

Fig. 5 shows the performance of the geothermal power plant with increasing steam content when the original steam turbine is replaced with a higher capacity. The rated capacity of the new turbine is assumed $42 \mathrm{MW}$ with the maximum power $47 \mathrm{MW}$. It is evident from the figure that such an upgrade results in significant improvement in power output. However, it is associated with large capital investment. 




Fig. 2. Theoretical power for the base case as a function of resource enthalpy

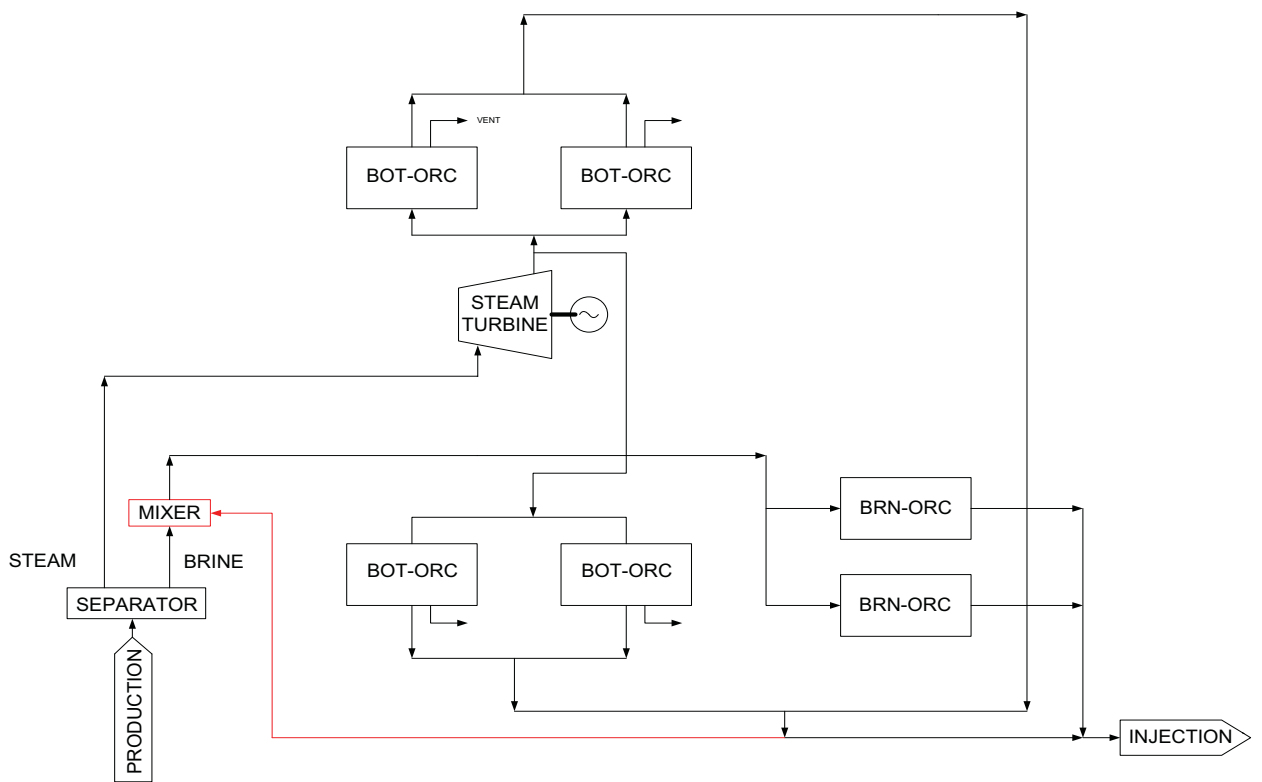

Fig. 3. Adaptive design for an increased flow of geothermal fluid

\subsection{Case Study 3: constant flow of geothermal fluid and lowered reinjection temperature}

In case 1, more geothermal fluid was used to overcome the problem of reduced brine in BRNORCs which results in utilization of the resource at a higher rate. The reinjection temperature of the geothermal brine is not affected much. In the base case, the reinjection temperature is about $125^{\circ} \mathrm{C}$. The minimum recommended reinjection temperature of the site is about $80{ }^{\circ} \mathrm{C}$ to prevent silica formation. So there is a possibility of further extracting heat from the reinjected brine.

The alternative design would look the same as Fig. 3. However, the geothermal resource is utilized at constant rate i.e. mass flow of geothermal fluid to the plant is the same as the base case. The plant performance would look like the same as Fig. 4 but the reinjection temperature will change. Fig. 6 shows the corresponding reduction in reinjection temperature. It is clear from Fig. 6 that it is possible to stabilize the brine flow rate of the BRN-ORCs and consequently power output by keeping the reinjection temperature within an acceptable limit $\left(80^{\circ} \mathrm{C}\right)$. 


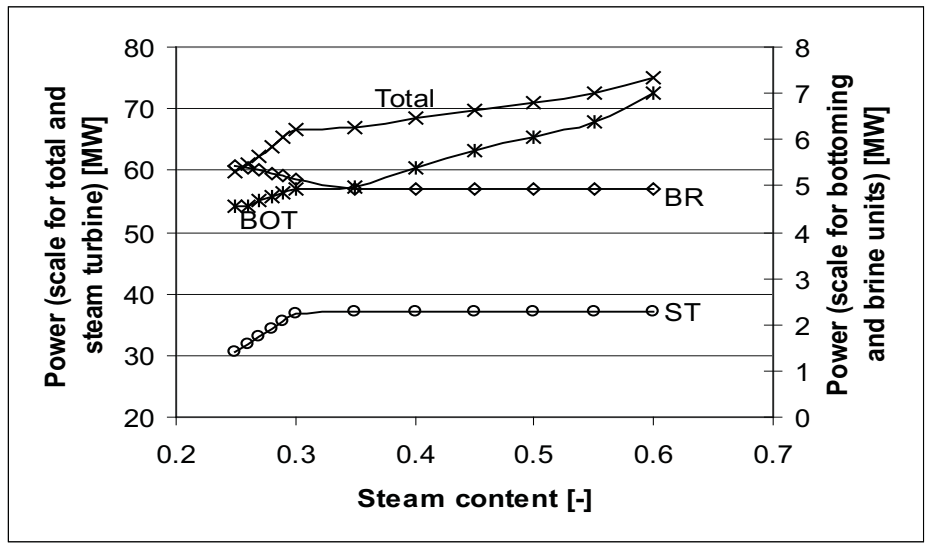

Fig. 4. Theoretical power for base case with increased mass flow of geothermal brine to keep the brine flow rate constant for the BRN-ORC as function of resource enthalpy



Fig. 5. Theoretical power of the geothermal power plant with a higher capacity steam turbine

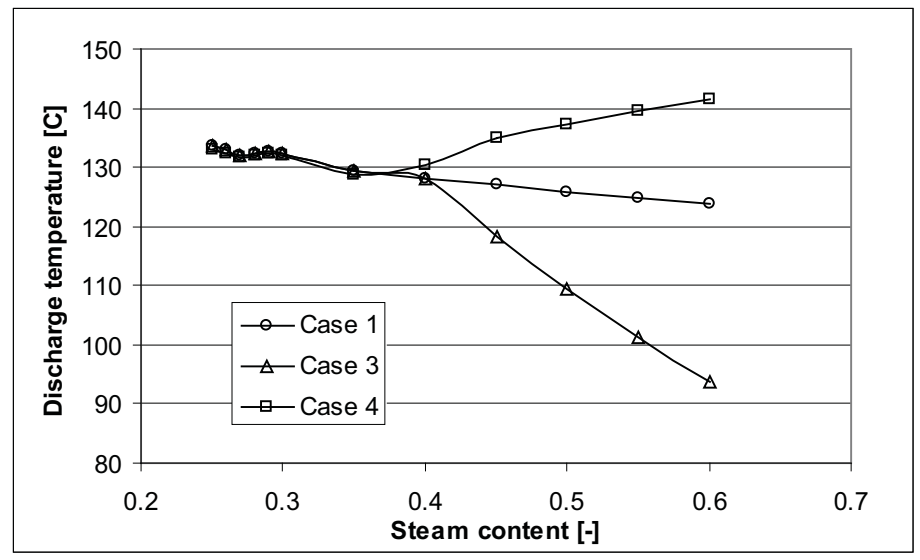

Fig. 6. Theoretical reinjection temperatures for case 1, case 3 and case 4

\subsection{Case study 4: constant flow of geothermal fluid with excess steam (50/50)}

It was stated earlier that the steam turbine has a power producing limit. Beyond this limit, the steam turbine cannot utilize the excess steam and the consequence is a higher discharge enthalpy. Another possible alternative is depicted in Fig. 7. The excess steam can be bypassed and used to reheat the condensate collected from the BOT-ORCs. The results of mixing excess steam (50\%) and condensate (50\%) are presented in Fig. 8. It is clear from Fig. 8 that 
the reheating of the condensate by excess steam mitigates the reduced brine for the BRNORCs. The reinjection temperature is not reduced by this approach (Fig. 6).

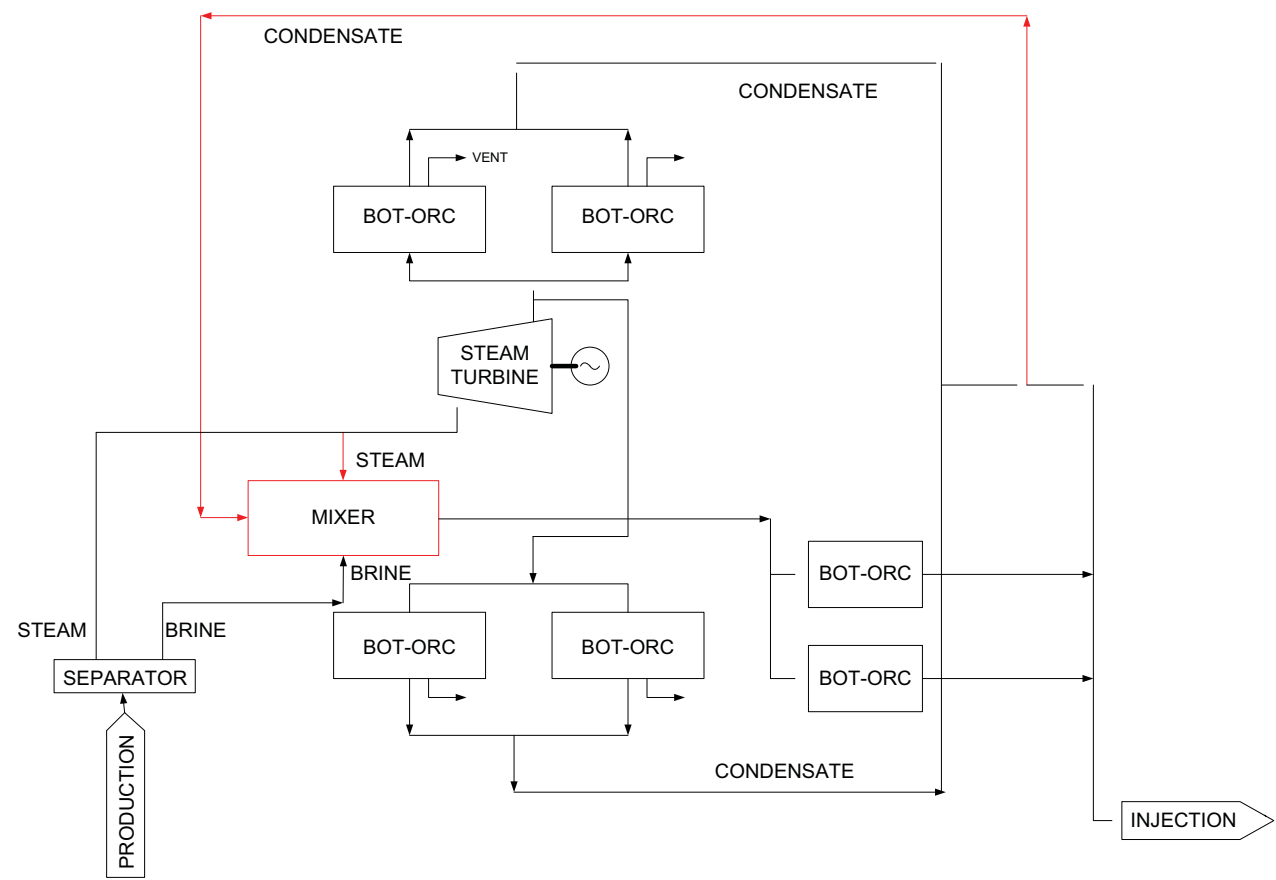

Fig.7. Adaptive design for a constant flow of geothermal fluid and regenerative heating



Fig. 8. Theoretical power of the geothermal power plant and constant mass flow of geothermal brine with regenerative heating of the brine by excess steam

\section{Discussion and conclusion}

This paper has introduced an alternative design approach that takes into account possible changes in future resource characteristics. As geothermal power plants are very capital intensive and it is not very easy to change a plant to adapt to resource characteristics different from the original design, keeping provision for future resource characteristics can be very effective. Although, the initial investment cost might go up as a consequence of adaptive design, over the life span of the plant the total benefit may be greater. A proper cost benefit analysis is necessary to identify the economic benefit. There are four case studies presented in this paper that analysed various possible options of the hypothetical power plant depending on the hypothetical changes in resource characteristics. The results show provisions that could be kept in the plant for future resource characteristics. The next phase is to do a cost benefit 
analysis of these options and select the optimum option. In this paper we have only discussed adaptive design approach for increasing resource enthalpy. Similarly, adaptive design for a decreasing resource enthalpy can also be carried out which will provide different provision for the geothermal power plant. One such provision is that one or more of the BOT-ORCs can be designed in such a way that they can be used as BRN-ORCs when geothermal resource enthalpy reduces to utilize the increased brine available.

\section{References}

[1] IEA, World Energy Outlook. 2008: International Energy Agency.

[2] Barbier, E., Geothermal energy technology and current status: an overview. Renewable and Sustainable Energy Reviews, 2002. 6(1-2): p. 3-65.

[3] DiPippo, R., Second Law assessment of binary plants generating power from lowtemperature geothermal fluids. Geothermics, 2004. 33(5): p. 565-586.

[4] Chen, H., D.Y. Goswami, and E.K. Stefanakos, A review of thermodynamic cycles and working fluids for the conversion of low-grade heat. Renewable and Sustainable Energy Reviews, 2010. DOI:10.1016/j.rser.2010.07.006

[5] Bombarda, P. and M. Gaia. Geothermal Binary Plants Utilising an Innovative NonFlammable Azeotropic Mixture as Working Fluid. in Proceedings 28th NZ Geothermal Workshop. 2006.

[6] Madhawa Hettiarachchi, H.D., et al., Optimum design criteria for an Organic Rankine cycle using low-temperature geothermal heat sources. Energy, 2007. 32(9): p. 1698-1706.

[7] DiPippo, R., Ideal thermal efficiency for geothermal binary plants. Geothermics, 2007. 36(3): p. 276-285.

[8] Sohel, M.I. and M. Jack, Efficiency improvements by geothermal heat integration in a lignocellulosic biorefinery. Bioresource Technology, 2010. 101 p. 9342-9347.

[9] Sohel, M.I., et al., An iterative method for modelling the air-cooled organic Rankine cycle geothermal power plant. International Journal of Energy Research, 2010. DOI: 10.1002/er.1706

[10] Sohel, M.I., et al., Dynamic Modelling and Simulation of an Organic Rankine Cycle Unit of a Geothermal Power Plant. Proceedings World Geothermal Congress 2010 Bali, Indonesia, 25-29 April 2010.

[11] Atrens, A.D., H. Gurgenci, and V. Rudolph, Electricity generation using a carbon-dioxide thermosiphon. Geothermics, 2010. 39(2): p. 161-169.

[12] Atrens, A.D., H. Gurgenci, and V. Rudolph, CO2 Thermosiphon for Competitive Geothermal Power Generation. Energy \& Fuels, 2008. 23(1): p. 553-557.

[13]DiPippo, R., Geothermal Power Plants: Principles, Applications and Case Studies. 2005: Elsevier Ltd.

[14]RJVL, ROTOKAWA GEOTHERMAL DEVELOPMENT Resource Consent Applications and Assessment of Environmental Effects. 2007, Rotokawa Joint Venture Limited, C/- Mighty River Power Limited, 160 Peachgrove Road, PO Box 445, HAMILTON, New Zealand.

[15] MathWorks, www.mathworks.com. 2008.

[16]REFPROP. National Institute of Standards and Technology (NIST), 2007. Available from: http://www.nist.gov/. 